\title{
Lecturers' Appraisals of English as a Lingua Franca in European Higher Education Settings
}

\author{
Nashwa Nashaat-Sobhy ${ }^{1}$ \& Davinia Sánchez-Garcia ${ }^{2}$ \\ ${ }^{1}$ Universidad Politécnica de Valencia, ${ }^{2}$ Universidad Complutense de Madrid \\ nash@idm.upv.es; mdsgarcia@ucm.es
}

\begin{abstract}
In this chapter we analyzed lecturers' attitudes towards using English in European Higher Education settings. Twenty-eight university teachers were brought together from thirteen universities across six European countries for an online training for teachers in English Medium Instruction (EMI) settings. The lecturers' written exchanges about English as an academic Lingua Franca (ELF) in one of the training modules were the target of our study. These exchanges (110 posts) were coded and analyzed using Martin and White's (2005) Appraisal Theory, which is a model of evaluation within the general theoretical framework of systemic functional linguistics. In this framework, affect, judgement and appreciation are regarded as regions (types) of feelings in interpersonal language that reflect attitude (positive or negative). The results showed that teachers' exchanges about ELF are interwoven with other types of English, in which they discussed different stakeholders and aspects of English, towards which their attitudes vary, which points to the multidimensionality of attitudes towards EMI. The results also show that appreciation and judgment regions were used more than affect in their language when discussing the use of English in Higher Education (HE).
\end{abstract}

Keywords: English as a Lingua Franca (ELF), attitude, appraisal theory, judgement, appreciation, affect, higher education 
One of the recent recurrent themes in language and education research concerns the perceptions and attitudes of students and lecturers about the growing use of English in Higher Education (HE) (Cots et al., 2014; Doiz et al., 2012), also referred to as the 'Englishization' of HE (Lanvers \& Hultgren, 2018; Smit, 2017). This term reflects the increasing dominance of English as "the" medium of instruction in European universities seeking internationalization; an on-the-rise trend fueled by the $\mathrm{HE}$ Bologna agreement, which has made the national $\mathrm{HE}$ systems in Europe (EU) more compatible and has allowed for the transfer of credits and learning experiences across transnational institutions (Knight, 2004). Internationalization, as a process, subsumes devising language policies (Spolsky, 2003), whether explicit and implicit, that emerge from language beliefs or ideologies, language practices, and management decisions (pp. 39-40). These policies and decisions are often steered in a top-down fashion (i.e., regulations and procedures) which places the burden on the involved community of practice (i.e., lecturers and students) to acclimatize and cope with the required language-related changes that those policies entail.

Lecturers and students in many of these institutions initially welcomed the shift to teaching in English, but as Airey and Linder (2008) point out, this may change, depending on the effects teaching and learning in English will have on the learning environment, and on whether English is perceived as a competing or a complementary language (Dafouz \& Smit, 2016). The degree to which English is embraced depends on what its users will consider (in)adequate and (un)worthy (Gnutzmann \& Intemann, 2008).

Speaking specifically about the dimensions that university teachers ${ }^{1}$ value, appreciate or feel strongly about in relation to the language of instruction is an important topic that affects their feelings and well-being; for instance, teachers emotions and classroom practices were found to be negatively affected when imposed on with policies and reform agendas (e.g., Van Veen \& Sleegers, 2006), which could apply to any group of teachers who see changes as top-down impositions that disregard teacher preparation and/or personal opinion. Therefore, in this study, we set out to explore the attitudes of lecturers in various EU countries towards using English in academic settings. Our aim is to come to a better understanding of the dimensions towards which they form an attitude when using English, and the linguistic resources they draw on to express attitude in their discourse.

That lecturers would have different views on English as a medium of instruction (EMI) is not surprising since its pedagogical benefits as a medium of instruction have not been fully established by research yet (Dearden, 2015). Its effectiveness as a medium for learning depends on factors like the availability of interaction opportunities in the classroom, the alignment of interactions with the intended pedagogical goals (Sánchez-García, 2020), the ability of the students to express themselves in English (Lo \& Macaro, 2015), and it also depends on the role of students' first language in EMI (Nashaat-Sobhy, 2017). Another point of concern some lecturers may have is deciding which variety or register of English to use in their EMI classrooms (for more on this point, see Young \& Walsh, 2010). For example, teachers who studied English as a foreign language (EFL) for many years may regard approximating native speaker standards as necessary despite this no longer being the norm in international EU higher education settings (Jenkins et al., 2001; Modiano, 2000).

\section{LITERATURE REVIEW}

\section{The Purpose of English in European Higher Education}

EU universities normally choose English as the language for overseeing and conducting student and staff mobility across-borders, curricular harmonization, and for international research collaboration (Dafouz \& Smit, 2016). In this regard, English is used as a tool, or medium, through which these activities are conducted, and a vehicle through which non-language subjects are taught in order to encourage home internationalization. The umbrella term used for these contexts, where English is a pedagogical medium, is English as a Medium of Instruction (EMI). EMI is often adopted by universities where interactants are either competent language users, or where lecturers teach in English but avoid focusing on language-related issues like correcting students' mistakes (Unterberger, 2012). In contrast, Integrated Content and Language in Higher Education (ICLHE) is the term reserved for HE contexts where lecturers plan for language facilitation and adopt certain pedagogical practices that enable the students to learn the language of their fields of study (see Smit \& 
Dafouz, 2014 for a more thorough explanation of the differences between EMI and ICLHE). In either case, exposing students to English is believed to improve students' working knowledge of English and to boost their employability. Similarly, with both EMI and ICLHE, English is a tool that facilitates communication among students and lecturers of different L1s, and one that empowers students with the language of business, science, technology, and research (Berns et al., 2007). English is therefore the non-local lingua franca (ELF) students and teachers of different L1s use in both EMI and ICLHE contexts. In this article we use the term EMI, being the umbrella term.

\section{The Nature of ELF as Opposed to EFL}

ELF is generally defined as the use of English as an additional language in a non-English environment that facilitates communication among speakers of different first languages (the Vienna-Oxford International Corpus of English - VOICE), in multicultural settings, and where the native speaker is not excluded but whose presence is incidental (Jenkins, 2019). Consequently, ELF is common in academic settings, resulting from different nationalities being in contact.

This constant engagement in English among speakers of different first languages from which L1 speakers of English may be absent seems to have diminished the necessity to abide by native English norms of any standard English variety (e.g., British or American). European ELF speakers use expressions and conceptualizations that originally were not present in English, but that are understood by the speakers who use them. These speakers rarely use idioms or fixed expressions, and coin new words as they tend to transfer terms and expressions from their native languages (Pitzl, 2018). Furthermore, their English pronunciation may have an underlying European accent and intonation (see examples in Jenkins et al., 2001) that could require some accommodation from L1 speakers of English. The more these unconventional uses of English are adopted “discoursal nativization” (Jenkins et al., 2001; Modiano, 2000) — into different text modes (i.e., oral and written), the more they are seen as a colorful reflection of cultures in contact, and not as a deficient form of interlanguage (Selinker, 1972). With this understanding, speakers of ELF need not mimic standard varieties or assume a different identity when using English. This discoursal nativization, however, extends to changing grammatical structures like dropping the third person singular "s", using the present continuous tense when the present simple is required, an increased use of certain verbs (“make” and “do"), mixing the relative pronouns who and which, and placing prepositions where not required (Breiteneder, 2005; Cogo \& Dewey, 2006). Some scholars in the field perceive discoursal nativization as a natural development (e.g., Modiano, 2000, 2007) and believe that a strength of ELF is that it is fluid, flexible and intercultural (Dewey, 2007). Others disagree, and perceive non-native English speakers (NNES) as having the status of language learners who should turn to one of the standard English varieties of the Kachruvian inner circle (Kachru, 1985) — where English is a first language - for correct usage (e.g., Mollin, 2006).

EFL refers to settings in which English is learnt as an additional foreign language, but which in the past, and in certain circles to this day, subsumes that EFL speakers should strive to approximate a native variety and that unconventionalities are errors that require attention and correction (cf. Jenkins et al., 2001). This is important to clarify because there are ideological differences underlying the use of EFL and ELF, and to clarify that English is not a monolith. Jenkins (2006) refers to EFL and ELF as two phenomena from two distinct paradigms: respectively, Modern Foreign Languages, which benchmarks learning to native standards for certification, and Global Englishes, in which NNESs constitute the majority of speakers of English. This explains why there are different opinions about the (un)importance of deviating from the native norms. That ELF is linked to Global English and its subsequent purposes, such as internationalization, may be the reason it is accepted as the norm for activities like transnational collaboration in projects, research and scientific publications, or in classroom discussions, where there are interpersonal and social interactions. In contrast, ELF is accepted less when perceived as a substitution for the English of the educated speaker, native or not (Gnutzmann et al., 2015; Jenkins, Cogo \& Dewey, 2011), given that EFL has been traditionally seen as the pathway for NNES to achieve a high level of language proficiency and academic literacy (Mauranen et al., 2010). 
The takeaway message here is that English has different types (ELF, EFL, \& Academic English), with different aspects, contextual functions and underlying ideologies, where some are more (dis)favored. Therefore, when lecturers express their attitude towards English, we understand it to be a reflection on all or some of these differences. It is common among teachers, however, to discuss English as if it were a single mass, especially nonlanguage teachers, who are not likely to think about the matter unless made aware of the differences.

\section{Previous Studies on Lecturers' Attitudes Towards English in HE}

The presence of English in the EU in general and in European HE institutions in particular is well documented (e.g., Doiz et al., 2012; Gnutzmann et al., 2015); yet, only an anecdotal number of studies explicitly target lecturers' attitudes towards the use of English. These studies, however, do not offer a conceptual nor an operational definition for attitude as a construct (e.g., Dearden \& Macaro, 2016; Jensen \& Thøgersen, 2011). Other studies have explored attitude-related topics like lecturers' “perceptions” (e.g., Aguilar and Rodriguez, 2012), lecturers' "views" regarding their self-attributed duties, training preferences, assessment and internationalization issues (e.g., Aguilar, 2017), and lecturers' "opinions” (e.g., Doiz et al., 2012) and their "experiences and behaviours" in EMI classes (e.g., Vinke, 1995; Klaassen, 2001). The researchers in these studies relied on questionnaires and/or interviews to elicit responses from lecturers on a number of predetermined issues like whether they are in favor of moving forward with EMI, their beliefs regarding their own linguistic competence and that of their students, as well as the difficulties experienced when teaching and learning in English. Another point which appeared is whether English is perceived as a threat to other languages. First, we review those studies that explicitly targeted lecturers' attitudes.

In Jensen \& Thøgersen (2011), the researchers examined lecturers' attitudes at one of Denmark's largest universities using a 17-item closed questionnaire. The questionnaire was based on themes extracted from a former debate among the teaching staff about the increasing use of English in research and $\mathrm{HE}$, and also the hypothesis that younger lecturers, and lecturers with a higher teaching load in
English, have a more positive attitude towards the increasing use of English in HE, which was supported by the findings of their study. Equally important in this study was their realization that attitude is composed of several dimensions and related themes that lecturers may be in favor of (e.g., English is important for internationalization) or against (e.g., being concerned that Danish is not the language of learning).

Another study in which the researchers explicitly state interest in lecturers' attitudes towards EMI is Dearden and Macaro (2016). They interviewed 25 teachers across Austria, Italy and Poland with focus on the themes of internationalization, resourcing, and on the levels of English proficiency lecturers believed necessary for effective EMI teaching. For the most part, the lecturers were in favor of EMI and of increasing the number of courses taught through English, despite the challenges. Language proficiency emerged as an issue as they voiced their concerns with regards to students' and teachers' linguistic competence, but no specific threshold for joining EMI programs was recommended as they considered it a matter beyond the specialization of non-language content lecturers. The Italian group voiced concerns regarding language-loss, seeing that when a language is no longer used in academia, it suffers. Dearden and Macaro (2016), like Ball and Lindsay (2012) and Aguilar and Rodriguez (2012), noted that many lecturers lack awareness regarding the need to change pedagogy if the aim is to help students cope with content taught through an additional language. A similar issue was also voiced in a study by Carroll-Boegh (2005), in which concerns about the linguistic competences of teachers and students in Danish universities were voiced, and hence the quality of teaching as a result.

Other studies that targeted lecturers' perceptions, views and opinions were mostly from the Spanish HE context where more than one language is often used for teaching, including Spanish, Catalan, Basque, and English. For example, Aguilar and Rodriguez (2012) explored the perceptions of 17 Spanish/Catalan Engineering lecturers about using English for teaching and learning. The researchers interviewed the lecturers about their EMI experience after their first semester of teaching through English. During that semester, the lecturers and researchers held meetings in which content and language integrated learning (CLIL) as a teaching approach was also discussed. 
CLIL as an approach has the dual focus of learning the nonlanguage content subjects as well as the additional language through which these subjects are taught (Coyle et al., 2010). Lecturer responses revealed they sometimes felt limited; for instance, two of the lecturers mentioned not having the linguistic resources to reformulate information during lectures without prior preparation, and that their capacity to think on their feet to find a precise word or expression in class is limited. Similar comments were reported by Ball and Lindsay (2012), who see that some lecturers are concerned with their own linguistic shortcomings at the expense of being concerned with students' learning. Despite lecturers' shortcomings and concerns, in Aguilar and Rodriguez (2012), they were reluctant to receive methodological training, which as reported may be due to lack of incentives and support by the university for the lecturers opting to teach through English.

In the Basque and Catalan context, Doiz et al. (2012) explored the opinions of five lecturers about multilingualism from different disciplines who were invited to a discussion group about multilingualism and EMI in their university. In this discussion, the lecturers affirmed their beliefs in the importance of multilingual practices. These lecturers reflected on both positive and negative consequences of teaching through English. One of the positive consequences was the opportunity to teach in English, that English attracts foreign students, and that it facilitates the teachers'/students' participation in exchange programs. They also stressed the importance of English for engaging in research. On the downside, the lecturers voiced the ineffectiveness of the incentive system and the unwillingness of their colleagues to adopt EMI. With regards to students' performance, they complained of the heterogeneous levels of proficiency in the classroom and the general low level of English among the students and the higher preparation load they are burdened with when teaching in English.

In the same vein but in a Dutch setting, Vinke (1995) and Klassen (2001) surveyed lecturers' views about their teaching challenges and classroom/pedagogical behaviors. The lecturers in both studies reported their frustrations when not being able to find the words to convey nuances or to explain a point differently during explanations. The lecturers in Vinke's (1995) study also mentioned feeling linguistically challenged in English and the need for additional preparation time, and lecturers' positivity was related to whether they perceived themselves as good language switchers.

The overall impression from this review is that the use of English in academia is welcomed by most of the surveyed lecturers. It is generally regarded as a necessity arising from the unstoppable force of globalization and is viewed as indispensable for research and mobility (Doiz et al., 2012). In varying degrees across countries, lecturers also mention their wish to improve their competence in English, and sometimes see an opportunity in EMI to do so (Doiz et al., 2012), probably as a result of using English more (planning for instruction and delivering content knowledge). The challenges are also more or less similar across the different contexts that were reviewed. There seems to be a consensus that a certain level of language proficiency is needed for both students and teachers, without which EMI is a challenge and burden (Aguilar \& Rodriguez, 2012; Klaassen, 2001; Vinke, 1995). The need to for more time to plan and prepare when teaching in English is another factor the lecturers mentioned (Doiz et al., 2012; Vinke, 1995). Some lecturers, moreover, see the increasing use of English as a threat to their national or regional language (Dearden \& Macaro, 2016). There is clearly a mixture of positive and negative attitudes, which is in line with Jensen and Thøgersen's (2011) observation about attitudes towards English in academia being neither dichotomous nor unidimensional.

Three issues surface in these studies: First, none attempted to define the construct of attitude, which is essential to identify the parameters to be measured. Second, it is unlikely that the lecturers who participated in these studies reflected on their understanding of what English means, which is part of attitude formation (Baird \& Baird, 2017), and in turn, these participants would not have had a shared understanding of English that being EFL, ELF, or academic English, and their answers would have been based on perceptions known to only them. Third, the participants were often lecturers in a single university or country, with anecdotal exceptions (e.g., Dearden \& Macaro, 2016).

We address these issues in this study. We define and analyze attitude from an SFL-based appraisal discursive approach (Martin \& White, 2005), we identify ELF as the target type of English, and the teachers in this study receive 
training in this regard, about which we give further details in the methods section.

\section{Attitude From a Discourse Appraisal Perspective}

Attitude as a measurable construct in social psychology and cognition is defined as "a psychological tendency expressed by evaluating a particular entity with some degree of favour or disfavour” (Eagly \& Chaiken, 1993, p. 1), which means that "evaluation" is a property of attitude that is observable through some form of expression. Accordingly, evaluative verbalizations (i.e., appraisals) in lecturers' exchanged discourse has great potential as a resource for attitude detection. Appraisals in discourse, as an area of research in applied linguistics, emerged as an interpersonal function in Systemic Functional Linguistics (SFL) (Halliday, 1985) in the 1990s from identifying literacy requirements in disciplinary discourses (e.g., science, history). Appraisal in discourse was then expanded into Appraisal Theory (Martin \& Rose, 2003; Martin \& White, 2005), where attitude is identified as an important domain defined as negative or positive values that the speaker associates to emotional responses about participants and processes (Martin \& White, 2005) about other people, objects, actions and so forth. Attitude, following an SFL-based appraisal approach, is expressed in discourse through "regions of feeling” (Martin \& White, 2005), or types, that are classified into:

(a) Affect: verbalizations including "affect" that answer the question, "do we feel happy or sad", confident or anxious, interested or bored”? (p. 42), and why (p. 47). They deal with statements that include:

\section{i. dis/satisfaction \\ ii. ill/confidence \\ iii. dis/inclination = wish, want, keen}

(b) Judgement: evaluations of human behavior in relation to the established social norms. It revolves around what is moral, ethical and legal that we may admire or criticize, praise or condemn. Through judgement we assess others' normality, veracity, tenacity, propriety. (c) Appreciation: evaluations of objects, products, outcomes (rather than human behavior) by reference to aesthetic principles and other systems of social value. It detaches the experiencer (or the self) from the state of something to evaluate the appearance of something, its quality, composition, complexity and functionality.

To sum up, attitude in appraisal theory deals comprehensively with feelings that go beyond emotions (affect) and takes a social constructionist and cross-cultural approach to evaluation, which is most suitable for the methodology of this study. With this understanding of attitude in mind and in relation to the reviewed literature, we examine the attitudes in the discourse of a transnational group of lecturers from universities across Europe about the use of English in HE in general, with particular focus on ELF two main questions were posed:

1. What attitude(s) do these lecturers have towards English?

a. What attitude polarity do their comments exhibit?

b. What types of English do they refer to?

c. How do they express their attitudes?

2. What do these lecturers appraise when discussing ELF?

\section{METHODOLOGY}

\section{Context and Participants}

With the aim to train NNES lecturers to deal with the challenges and opportunities of teaching in/through English, Valcke and Romero Alfaro (2016) designed and led an online community of practice for lecturers across Europe to engage in an awareness raising training in English. The participants were paired in tandems - two or three teachers from different countries and disciplines - for 7 months on the learning platform Eliademy (an asynchronous virtual learning environment) in 2017-2018 (the course's $4^{\text {th }}$ edition). The training was divided into six modules covering 
different EMI-related topics, one of which was ELF in the international classroom, which was covered over the span of a month in the form of three tasks:

- Pre-task: in which participants had to read an article chosen by the course leaders and watch a video on the topic individually.

- Task: participants met online with their corresponding e-tandem partner via Skype to orally discuss the content of the article and the video in the pre-task. The exchanges were prompted by questions based on the pre-task materials to jump-start their interactions.
- Post-task: after interacting with their tandem partners, each participant wrote their main personal reflections and posted them in the discussion forum. The instructions indicated they had to comment on other teacher participants' contributions (a minimum of two).

Our data is composed of all the exchanges resulting from the post-task module on ELF, accessed with the participants' informed consent. These exchanges took place among the twenty-eight teacher participants that enrolled. The lecturers were affiliated with thirteen HE institutions in six European countries (Table 1) and had proficiency levels ranging from $\mathrm{B} 2$ to $\mathrm{C} 1+$ on the CEFR scale (Common European Framework of Reference, 2001).

Table 1. The Countries of Origin of the Teacher Participants and the Number of Home Institutions in Each

\begin{tabular}{lcc}
\hline Country & Number of home institutions & Number of Participants \\
\hline Spain & 3 & 10 \\
Sweden & 2 & 7 \\
Belgium & 3 & 4 \\
Finland & 2 & 3 \\
Netherlands & 2 & 3 \\
Denmark & 1 & 1 \\
\hline
\end{tabular}

\section{Data and Data Analysis}

The module on ELF targeted teachers' language beliefs and practices in the EMI class, English language and its role as a lingua franca and how their understanding of ELF impacts their teaching, especially in the international class ${ }^{3}$. A total number of 110 entries were gathered and uploaded to the UAM-CORPUS Tool (O’Donnell, 2008). To code the data, the researchers built a data-driven coding schema. Our codes were based on Martin and White's (2005) classification of attitude. With regards to the unit of analysis, Martin and White (2005) explain that appraisal is based on discourse semantics, hence the unit is "concerned with meaning beyond the clause" in which persons, other entities and states of affairs "are introduced and kept track of until evaluation is established and amplified" (p. 9). Each mention of English including an appraisal ${ }^{4}$ (in relation to a type, an aspect or a stakeholder) was considered a unit (a segment), resulting in a total of 403 segments within the 110 posts. The two researchers also agreed on their classifications, as either affect, judgement or appreciation, until reaching full consensus. The final coding scheme (Figure 1) included:

(a) Positive and negative attitudes and ambiguous statements. "Positive" refers to not only what is "good", but also what they consider "easy" and "beneficial". Similarly, Negative refers to what they consider "bad, difficult and harmful". Ambiguous statements are those not carrying a clear polarity 


\section{Figure 1. The Coding Scheme Used in Analyzing Lecturers' Attitudes Towards English}

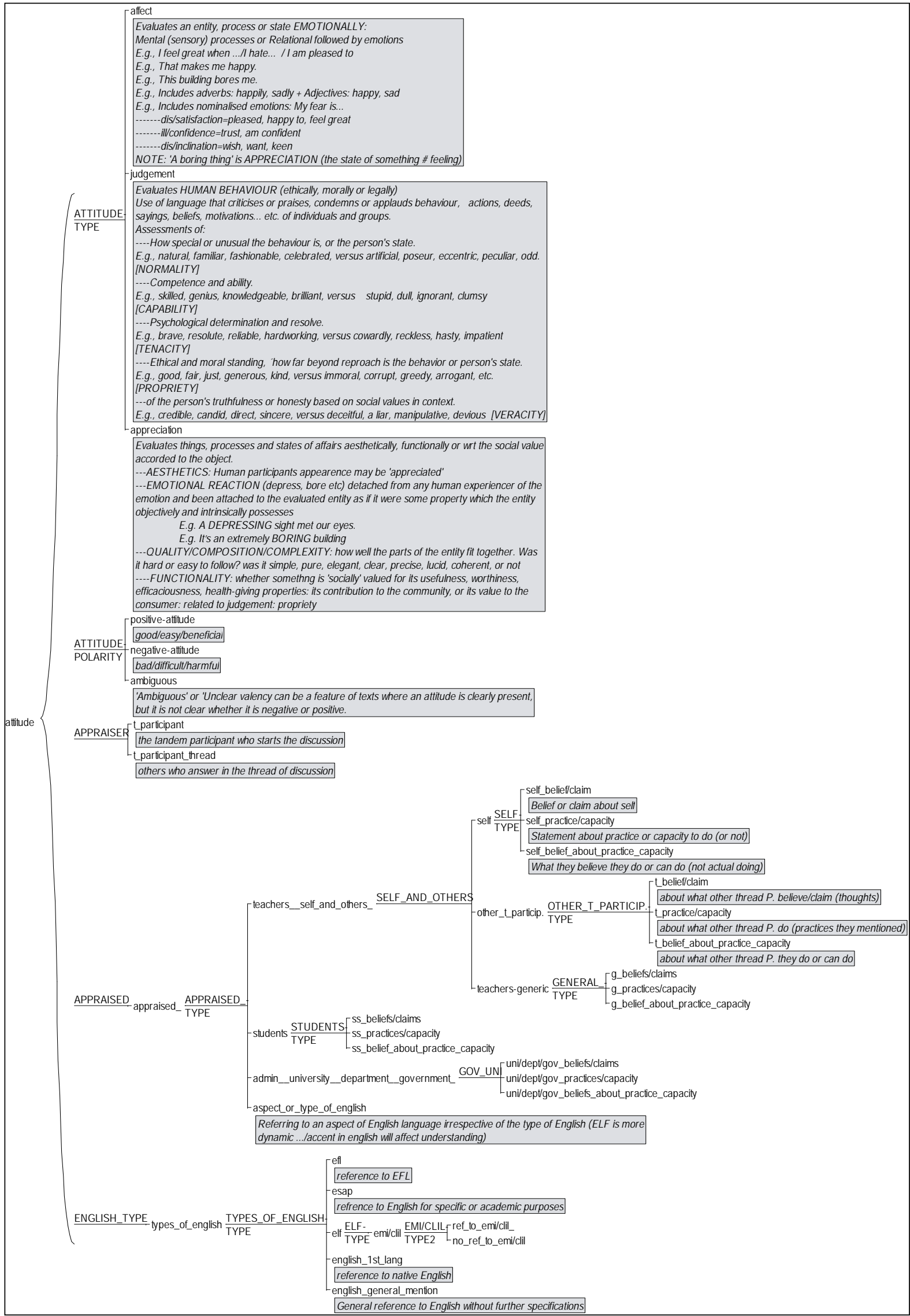


(b) Types of English mentioned (EFL, English for specific and academic purposes or ESAP, ELF with and without reference to the EMI class; English as a native language, and English without specifying any of the above neither implicitly nor explicitly). Lecturers referred to them in relation to ELF whether to contrast types or to voice different attitudes, which required its inclusion in the schema.

(c) The appraiser (the teacher starting the discussion or other teachers in the thread). All teachers started a thread (as instructed) and others replied to the first entered post.

(d) The appraised are the agents or the aspects the lecturers appraised in their responses. This included teachers, including self and others; students; and university administration /department - to which we included aspects of English as a language that they appraised at times. The appraised was further subclassified into whether the theme was beliefs/claims or practices/competences.

Examples of the above codes will be presented among our findings in the Results and Discussion sections. For the statistical treatment of the data, the UAM corpus tool was used to provide a non-parametric Chi square test at three confidence levels $(p=<0.05)$ : Weak significance $(90 \%)$ with the symbol +; medium significance (95\%) as ++; and strong significance $(98 \%)$ as +++ .

\section{RESULTS AND DISCUSSION}

\section{Lecturers’ Attitudes Towards Using English}

To answer the first question, we looked at the polarity of their attitudes towards English in general. We also accounted for the mentions of the different types of English in the discussions (EFL, ESAP, ELF; native English; unspecified English) in order to see what types the lecturers referred to when asked about English, and we looked into the ways they express their attitudes; through affect, judgments or appreciation more. The results presented in Table 2 show that out of a total of 403 coded segments, 45.91\% were positive and $33.00 \%$ were negative (see examples 1 \& 2). The remaining 21.09\% instances were ambiguous (see example 3). For each of the categories, we provide a prototypical excerpt as an example. These examples will be numbered.

1. Example of positive value: "This may be appreciated by some of the students who are not yet so practiced in ELF" (a practice that is referred to as possibly beneficial).

2. Example of negative value: "I get annoyed by the poor use of language” (a lecturer complaining about how students' low language performance affects her judgement of their contentknowledge).

3. Example of ambiguous polarity: "When I studied English at school, I did feel the need to use English to interact with native speakers" (a statement with no attached positive or negative value).

As for the types of English they refer to in their comments (see examples 4 to 7), these were: ELF (53.35\%), EFL (26.80\%), unspecified English (10.92\%), ESAP (4.96\%) and native English (3.97\%).

4. Example of ELF and EFL: "I think ELF is more dynamic than English as a foreign language due to the different cultural impact" (this is one of the few examples in which both are compared to each other).

5. Example of English (unspecified): "My attitude to the English language is very positive" (the rest of the discourse does not help place the mention of English under a specific type).

6. Example of ESAP: "My attitude to the English language has been a language for academic purposes" (the speaker then continues to say that after a certain point he/she used it later for communication, but not before)

7. Example of Native English: "I find it less difficult to understand those whose mother tongue is English" (some participants agreed to this statement and others disagreed). 
Table 2. Lecturers' General Attitude Towards English

\begin{tabular}{lcc}
\hline Feature & Total $N$ of coded segments \\
& $N=403$ & $\%$ \\
\hline ATTITUDE-TYPE & 65 & 16.13 \\
$\quad$ affect & 142 & 35.24 \\
judgement & 196 & 48.64 \\
$\quad$ appreciation & & \\
ATTITUDE-POLARITY & 185 & 45.91 \\
$\quad$ positive attitude & 133 & 33.00 \\
$\quad$ negative attitude & 85 & 21.09 \\
$\quad$ ambiguous & & \\
ENGLISH_TYPE & 403 & 100.00 \\
$\quad$ types of English & & \\
TYPES_OF_ENGLISH-TYPE & 108 & 26.80 \\
$\quad$ EFL & 20 & 4.96 \\
ESAP & 215 & 53.35 \\
ELF & 16 & 3.97 \\
$\quad$ native ENGLISH & 44 & 10.92 \\
$\quad$ unspecified ENGLISH & & \\
\hline
\end{tabular}

With regards to the linguistic construction of attitude (see examples 8 to 10), there were more instances of appreciation (48.64\%) followed by judgement (35.24\%) and finally affect (16.13\%). See Figure 1 for more details.

8. Example of Appreciation: "It is difficult to judge whether not mastering the instructions is due to language skills or due to lack in other skills in the subject taught” (appraising a practice/process as complex).

9. Example of Judgement: “It doesn't have to be fully mastered" (evaluating normality and capability).

10. Example of Affect: "I need to get objective feedback on my English” (expressing inclination; wanting, needing, etc.).

Table 3 also shows a more in-depth look at what lecturers considered positive and negative only (ambiguous attitudes were excluded). With regard to types of English, they all received positive and negative values, with strong significant differences between these values for ELF, EFL and native English.
ELF received significantly more positive comments (68.82\%) $\{\mathrm{X} 2=36.65\}$ [negative comments (34.59\%)]. It is important to note that their comments about ELF mostly refer to using it in EMI; there we see similar positive and negative value percentages (72.00\% and $82.61 \%)$, in which the negative values appear slightly higher than the positive ones (see examples $11 \& 12$ ).

11. Example of Positive ELF value: "The advantage of ELF is precisely that it avoids that kind of local usage of the language.”; "The mistakes in English could be, should be, tolerated for the sake of communication" (referring to inner circle varieties, the lecturer appreciates the functionality of ELF then uses judgment to evaluate the focus on communication).

12. Example of Negative ELF value: "This is a more important challenge in my class [to create a more dynamic, open, dialogue-based and culturalbased context]" (this is part of a thread in which one of the lecturers replies to the comment between brackets [ ], judging the anticipated difficulty attending to or making use of ELF features in the classroom). 
Turning to other types, EFL and native English received significantly more negative comments; respectively, (39.85\%) $\left\{X^{2}=20.35\right\}$ and (7.52\%) $\left\{X^{2}=6.92\right\}$. Unspecified English, which were the comments that were not subclassified under any of the other types also received significantly more negative comments of moderate statistical strength (15.04\%) $\left\{X^{2}=4.59\right\}$ (see examples in 13 to 15$)$.

13. Example of EFL: "Some of us 'secondary' English speakers feel very self-conscious about our accents.” (a lecturer uses a sensory verb to express feeling apprehensive when pronouncing English)

14. Examples of Native English: "We need to be wary of the possibility of colonization by language and just concentrate on the mutually respectful communication”; "I had a teacher with a strong distaste for 'Globish', so English has always meant Oxford or BBC to me” (a lecturer expresses an inclination towards ELF and away from being limited by a specific variety. In the second example, another expresses being led to think that non-standard varieties are distasteful)

15. Example of Unspecified English: "It is hard to understand what the student means when the message is poorly expressed] (the context of the emotional reaction/appreciation to the message being "poorly expressed" was not clear whether it was in ELF, EFL, or other).

Table 3. A Focus on the Features Assigned Positive and Negative Values

\begin{tabular}{|c|c|c|c|c|c|c|}
\hline \multirow[t]{2}{*}{ Feature } & \multicolumn{2}{|c|}{ Positive attitude } & \multicolumn{2}{|c|}{ Negative attitude } & \multirow[b]{2}{*}{$X^{2}$} & \multirow[b]{2}{*}{ Significance } \\
\hline & $N$ & $\%$ & $N$ & $\%$ & & \\
\hline ATTITUDE-TYPE & 186 & & 133 & & & \\
\hline affect & 23 & 12.37 & 31 & 23.31 & 6.6 & +++ \\
\hline judgement & 59 & 31.72 & 43 & 32.33 & 0.01 & \\
\hline appreciation & 104 & 55.91 & 59 & 44.36 & 4.14 & ++ \\
\hline TYPES_OF_ENGLISH-TYPE & 186 & & 133 & & & \\
\hline $\mathrm{EFL}$ & 32 & 17.20 & 53 & 39.85 & 20.35 & +++ \\
\hline ESAP & 9 & 4.84 & 4 & 3.01 & 0.67 & \\
\hline ELF & 128 & 68.82 & 46 & 34.59 & 36.65 & +++ \\
\hline native ENGLISH & 3 & 1.61 & 10 & 7.52 & 6.92 & +++ \\
\hline unspecified ENGLISH & 14 & 7.53 & 20 & 15.04 & 4.59 & ++ \\
\hline ELF-TYPE & 128 & & 46 & & & \\
\hline ref_to_EMI & 96 & 75.00 & 38 & 82.61 & 1.11 & \\
\hline no_ref_to_EMI & 32 & 25.00 & 8 & 17.39 & 1.11 & \\
\hline
\end{tabular}

As for ESAP, though it received more positive comments (4.84\%) than negative ones (3.01\%), they were very few in comparison to other types, and no statistical differences were found.

The attitude type that significantly prevailed in the positive comments (without differentiating among the types of English) was "appreciation" (55.91\%) $\left\{\mathrm{X}^{2}=4.14\right\}$ and the attitude significantly prevailing in the negative comments was "affect" (23.31\%) $\left\{X^{2}=6.6\right\}$. With regards to "judgement", its use was divided between both polarities
[31.72\% in the positive comments and $32.33 \%$ in the negative comments].

The results from both tables (Tables $2 \& 3$ ) show that the lecturers tend to discuss English positively in more instances than not, but ELF is the type of English they significantly refer to positively when discussing the use of English in academic settings (Table 3). Nonetheless, their comments on ELF in relation to EMI were assigned positive and negative values almost equally, indicating they have issues with using ELF in classroom settings, which we will 
look at in the results of the second question below. With regards to EFL, some lecturers referred to a longstanding tradition of being taught about the supremacy of one variety (examples 13 \& 14), which contributed to the high statistical significance of negative polarity under EFL and Native English norms.

As for their construction of attitude, they used appreciation significantly more than judgment and affect and used it to express positive views mostly. Through affect, on the other hand, they mostly expressed negative views. They used judgement to express both polarities. In our view, the participants tapped into different regions of feelings at the mention of different types of English (subsuming different purposes and aspects), which was in turn reflected in their linguistic behavior (verbalizations of appreciation, judgments and affect). Their noticing and valuing of the qualities and functionality of ELF seemingly led to their appreciation for ELF, while their concerns seem to have triggered other regions of feelings that were conveyed as judgement and affect. These concerns were about their, and their students', worth as non-native users of the language, probably attached to older memories and notions they had about themselves as EFL learners, later coupled with other professional concerns like the need to invest more time and effort when preparing for teaching in English. From a psychological perspective, we find in Wilson et al.'s (2000, p. 104) dual attitude model support and clarification for our view:

Attitude toward the relationship does not fully replace the older, more habitual one and that the implicit and explicit attitudes are each expressed under different circumstances. [...]. The implicit attitude is habitual and automatic, it is the default response that is expressed when people do not have the capacity or motivation to retrieve the more recent attitude. The explicit attitude is expressed and acted on when people have the motivation and cognitive capacity to retrieve it.

According to Wilson et al.'s (2000) model, our lecturers' older and more habitual implicit attitudes towards English (particularly, EFL, native-standard use of English expected in academic settings) can coexist with other more recent implicit attitudes they have formed towards it for the international classroom (i.e., ELF in EMI). Both attitudes are retrieved in their discussions, depending on the purposes of English in focus.

\section{What Lecturers Appraise in ELF: The Celebrated and The Criticized}

The focus here is on how lecturers appraised ${ }^{5}$ themselves and others: students, administration (including departments and universities), and aspects of English they thought worth praising or criticizing in ELF. We shall refer to them as “appraised categories” (Table 4).

In ELF, the comments expressing positive attitudes were more than the negative ones in the four dimensions (teachers, students, administration and aspects of English). Also, appreciation and judgement (not affect) were mostly used in the construction of attitude. The categories that received the most appraisals in a descending order are described below with examples:

(a) Teachers (124 comments) with $73.39 \%$ positive comments. Lecturers mostly appraised their and others' practices and abilities (practices and beliefs).

16. Example of Positive value: "I don't think the quality of my teaching decreases, but totally the opposite. I teach technical courses and it is important to know the words in English. Thus, the Students learn very useful vocabulary in English that they will use in their professional career" (appreciating functionality).

17. Example of Negative value: "[ELF being the context] ... it makes me less flexible in my answers as I do not always am able to say what I think"; "I do feel that the teaching quality suffers sometimes"; "it influences the quality of my lessons" (not appreciating feeling limited in the classroom and seeing it as counterproductive).

(b) Aspects of English (28 comments) with 82.14\% positive comments.

18. Example of Positive value: "The concept of ELF seems rather familiar"; "the advantage is that we all use simple words and expressions" (appreciating a quality). 
Table 4. The Categories Appraised in ELF

\begin{tabular}{|c|c|c|c|c|c|c|c|c|}
\hline \multirow[t]{2}{*}{ FEATURE } & \multicolumn{2}{|c|}{ Teachers } & \multicolumn{2}{|c|}{ Students } & \multicolumn{2}{|c|}{ Administration } & \multicolumn{2}{|c|}{ Aspect of English } \\
\hline & $N$ & $\%$ & $N$ & $\%$ & $N$ & $\%$ & $N$ & $\%$ \\
\hline ATTITUDE-TYPE & 124 & & 17 & & 9 & & 28 & \\
\hline affect & 15 & 12.10 & 3 & 17.65 & 0 & 0.00 & 1 & 3.57 \\
\hline judgement & 39 & 31.45 & 7 & 41.18 & 5 & 55.56 & 4 & 14.29 \\
\hline appreciation & 70 & 56.45 & 7 & 41.18 & 4 & 44.44 & 23 & 82.14 \\
\hline ATTITUDE POLARITY & 124 & & 17 & & 9 & & 28 & \\
\hline positive attitude & 91 & 73.39 & 12 & 70.59 & 6 & 66.67 & 23 & 82.14 \\
\hline negative attitude & 33 & 26.61 & 5 & 29.41 & 3 & 33.33 & 5 & 17.86 \\
\hline TEACHERS (SELF_AND_OTHERS) & 122 & & 1 & & 0 & & 0 & \\
\hline self & 67 & 54.92 & 0 & 0.00 & 0 & 0.00 & 0 & 0.00 \\
\hline other teacher participants & 7 & 5.74 & 0 & 0.00 & 0 & 0.00 & 0 & 0.00 \\
\hline general & 48 & 39.34 & 1 & 100.00 & 0 & 0.00 & 0 & 0.00 \\
\hline SELF & 67 & & 0 & & 0 & & 0 & \\
\hline belief/claim & 13 & 19.40 & 0 & 0.00 & 0 & 0.00 & 0 & 0.00 \\
\hline practice/capacity & 24 & 35.82 & 0 & 0.00 & 0 & 0.00 & 0 & 0.00 \\
\hline belief about practice/capacity & 30 & 44.78 & 0 & 0.00 & 0 & 0.00 & 0 & 0.00 \\
\hline OTHERS & 7 & & 0 & & 0 & & 0 & \\
\hline belief/claim & 0 & 0.00 & 0 & 0.00 & 0 & 0.00 & 0 & 0.00 \\
\hline practice/capacity & 3 & 42.86 & 0 & 0.00 & 0 & 0.00 & 0 & 0.00 \\
\hline belief practice/capacity & 4 & 57.14 & 0 & 0.00 & 0 & 0.00 & 0 & 0.00 \\
\hline GENERAL & 48 & & 1 & & 0 & & 0 & \\
\hline belief/claim & 4 & 8.33 & 0 & 0.00 & 0 & 0.00 & 0 & 0.00 \\
\hline practice/capacity & 5 & 10.42 & 0 & 0.00 & 0 & 0.00 & 0 & 0.00 \\
\hline belief about practice/capacity & 39 & 81.25 & 1 & 100.00 & 0 & 0.00 & 0 & 0.00 \\
\hline STUDENTS-TYPE & 1 & & 16 & & 0 & & 0 & \\
\hline belief/claim & 0 & 0.00 & 1 & 6.25 & 0 & 0.00 & 0 & 0.00 \\
\hline practice/capacity & 0 & 0.00 & 10 & 62.50 & 0 & 0.00 & 0 & 0.00 \\
\hline belief about practice/capacity & 1 & 100.00 & 5 & 31.25 & 0 & 0.00 & 0 & 0.00 \\
\hline UNI/DEPT/GOVERN & 0 & & 0 & & 9 & & 0 & \\
\hline belief/claim & 0 & 0.00 & 0 & 0.00 & 0 & 0.00 & 0 & 0.00 \\
\hline practice/capacity & 0 & 0.00 & 0 & 0.00 & 7 & 77.78 & 0 & 0.00 \\
\hline belief about practice/capacity & 0 & 0.00 & 0 & 0.00 & 2 & 22.22 & 0 & 0.00 \\
\hline
\end{tabular}

19. Example of Negative value: "ELF comprises many constantly changing variants...that emerge spontaneously in a given international group”; "why not keep teaching in one well-defined version (so students can develop their EFL)?” (evaluating ELF as chaotic and judging it is not beneficial for developing EFL)

(c) Students (17 comments) with $70.59 \%$ positive comments. The most appraised feature under this category were students' practices and abilities (relayed as facts).

20. Example of Positive value: "My international students are able to follow my teaching almost equal to the Danish students” (judging students' ability, but also appreciating the functionality of ELF).

21. Example of Negative value: "When I started teaching [subject] in English] my students were 
completely unable to translate certain sentences” (judging students lack of competence to use English in a certain way).

(d) Administration (9 comments) with $66.67 \%$ positive comments. The most appraised feature under this category were practices as well (relayed as facts).

22. Example of Positive value: "Some authorities in our university are concerned about making teaching in English a reality" (Judging the tenacity of authority's behavior).

23. Example of Negative value: "For my university, internationalization is a goal not a reality" (judging the veracity of authority's behavior).

The examples presented show a qualitative side of the data on ELF (in addition to the quantitative analysis - Table 4) in which the participants relayed both positive and negative attitudes. Lecturers' comments reflected a noticeably higher positive attitude when discussing ELF, irrespective of the category being appraised. This is attributed to ELF being a means to involve international students (see examples 20 \& 4). According to Doiz et al. (2012), ELF in academia can enable lecturers to manage and motivate students different linguistic and cultural backgrounds, which can enable teachers to have more dynamic classrooms. The lecturers in this study often stressed their appreciation for the relative ease, practicality, and familiarity of ELF (examples 9, 16 \& 18). The lecturers' cheering for ELF over EFL lies in the way it ideologically lends more importance to making meaning and interaction as opposed to focus on forms. Such features legitimize their deviation from any standard variety and through which some avoid feeling colonized or feeling a lack of confidence because of their accents (examples 11, 13 \& 14). On occasion, the lecturers also expressed positive attitudes towards the genuine efforts done by their universities to make EMI a reality (example 22).

Lecturers also tended to hold a negative attitude towards what generates feelings of concern and frustration, which is also noted in previous studies; for example, students' struggle with communication and/or content learning as a result of not having a minimum level of language proficiency (examples 2, $15 \& 21$ ) is also mentioned in Carroll-Boegh (2005) and Doiz et al. (2012); the additional effort that teaching through English requires from lecturers is mentioned in Doiz et al. (2012) and Dearden and Macaro (2016); and the difficulty of fostering dynamism at times and not being able to improvise or deviate from the script (examples 12 \& 17) is mentioned in Vinke (1995) and in Klassen (2001). Other points they assigned negative values to were in comments about not being able to detect whether learning problems are linguistic or content related (example 8); and the fact that some universities go through the motions of internationalization without genuine interest in the medium of instruction (example 23), the opposite of what others said before (example 22). A few of the lecturers said that ELF in comparison to EFL is chaotic in the sense of not belonging to a variety they can look up in a book (example 19), possibly with first language interferences whenever non-native speakers get together. This highlights an interesting contrast against the very description of discoursal nativization described by Jenkins et al. (2001) and Modiano (2001), mentioned earlier in this article.

\section{CONCLUSION}

To examine lecturers' attitudes towards English in European higher education settings, we analyzed the discourse of twenty-eight lecturers from thirteen universities in six countries. In comparison to the previous research that tackled the same topic, our study was novel in that the participants shared the concept of ELF prior to expressing their attitude(s) towards it (Baird \& Baird, 2017) and prior to data collection, which is a practice we found unmentioned in other studies. Second, we clarified what attitude means from a social psychological perspective (Eagly \& Chaiken, 1993, 2007) and in applied linguistics from an SFL appraisal perspective (Martin \& White, 2005) that we used to measure attitude (affect, judgment and appreciation), both positive and negative in the lecturers' exchanges about using English. Third, our participants are from a broader range of settings, which strengthens the representability of our findings.

The lecturers' discussions showed that English is composed of types with different purposes, aspects, advantages and disadvantages, which they tended to compare and contrast, and to which they have formed older and newer attitudes (Wilson et al., 2000). To clarify, they refer to EFL, native English, ESAP and ELF when discussing English, towards which they seem to have 
formed dual attitudes (positive and negative) in different moments. Some are old and habitual, related to their experiences as EFL learners and non-native users of the language, and others are more recent and related to ELF.

We also explained in this article how lecturers tap into different regions of feelings when expressing their attitude towards English in HE. We have shown how they resort to "appreciation" mostly when discussing positive aspects of ELF, and to "affect" to express their dissatisfaction; however, depending on the appraised category and aspects of usage being focused on - and towards which they have one attitude or the other - their focus can give the appearance of having skewed attitudes in favor of or against English. It is, therefore, important to take in all the appraised dimensions to understand their attitudes on the topic. For example, ELF may appear mainly celebrated if

1 In this study, 'teachers' and 'lecturers' irrespective of their academic rank are used interchangeably.

${ }^{2}$ Happy/Sad is a subtype that did not appear in the data.

3 The concept of "international classroom" is multi-faceted and varies across settings. Here it is understood as having international students and/or having international disciplinary content and/or including internationalized learning outcomes. the focus is on students in international classes, but it may appear disfavored when the focus is on teachers' perceived language competences. The concerns that the lecturers voice with regards to using ELF in HE requires genuine attention, and further conciliation between the goals of internationalization, language learning and content learning is still needed.

The analytical approach using appraisal theory in this study has made it possible to reach this level of specificity in identifying what the participants favor or disfavor, which we find important in future studies targeting teacher and student attitude. Future studies may also consider looking at, the language by which speakers adjust the force of their appraisal, i.e., “graduation” (Martin \& White, 2005, p. 35), and which we consider a limitation in our analysis.

4 Excluding the segments where the use of English is not mentioned, or is not the target of the appraisal; e.g., "I have been a teacher for $\mathrm{x}$ number of years, and I love teaching."

${ }^{5}$ Lecturers' comments not including appraisals or with ambiguous values were removed to account only for positive and negative ones. The total number of comments in ELF without ambiguous values $=174$.

\section{Notes on the authors}

Nashwa Nashaat-Sobhy is Assistant Professor at Universidad Politécnica de Valencia (UPV). Her research focuses on teaching and learning in integrated content and language contexts (CLIL and EMI) across different educational stages. She is a member of both GALE research group at UPV and the UAM-CLIL group at the Universidad Autónoma de Madrid (UAM).

Davinia Sánchez-García is a lecturer at Universidad Complutense de Madrid (UCM). Her research interests mainly focus on Englishmedium education (EME) in higher education. She is currently a member of the international project EQUiiP and the UCM research group EnglnHE, which studies the role of English in the internationalization of Spanish higher education to promote the professional development of university teachers.

\section{REFERENCES}

Aguilar, M., \& Rodríguez, R. (2012). Lecturer and student perceptions on CLIL at a Spanish university. International Journal of Bilingual Education and Bilingualism, 15(2), 183-197. https://doi.org/10.1080/13670050.2011.615906

Airey, J., \& Linder, C. (2006). Language and the experience of learning university physics in
Sweden. European Journal of Physics, 27(3), 553-560. https://doi.org/10.1088/01430807/27/3/009

Baird, R., \& Baird, M. (2017). English as a lingua franca: Changing 'attitudes'. In J. Jenkins, W. Baker, \& M. Dewey (Eds.), The Routledge handbook of English as a lingua franca (pp. 531-543). 
Routledge. https://doi.org/10.4324/978131571717 $\underline{3-43}$

Ball, P., \& Lindsay, D. (2013). Language demands and support for English-medium instruction in tertiary education. Learning from a specific context. In A. Doiz, D., Lasagabaster, \& J. M. Sierra (Eds.), English-medium instruction at universities: Global challenges (pp. 44-62). Multilingual Matters. https://doi.org/10.21832/9781847698162-007

Bolton, K., \& Kuteeva, M. (2012). English as an academic language at a Swedish university: Parallel language use and the "threat" of English. Journal of Multilingual and Multicultural Development, 33(5), 429-447.

https://doi.org/10.1080/01434632.2012.670241

Berns, M., Claes, M. T., de Bot, K., Evers, R., Hasebrink, U., Huibregtse, I., Truchot, C., \& van der Wijst, P. (2007). English in Europe. In M. Berns, K. de Bot, \& U. Hasebrink (Eds.), In the presence of English: Media and European youth (pp. 15-42). Springer. https://doi.org/10.1007/978-0-387-36894-8_2

Breiteneder, A. (2005). The naturalness of English as a European lingua franca: The case of the 'third person -s'. Vienna English Working Papers, 14(2), 3-26.

Carroll-Boegh, A. (2006). Internationalisation and teaching through English: A Danish perspective. Educate , 5(2), 19-30.

Cogo, A., \& Dewey, M. (2006). Efficiency in ELF communication: From pragmatic motives to lexico-grammatical innovation. Nordic Journal of English Studies, 5(2), 59-94.

https://doi.org/10.35360/njes.12

Cots, J. M., Llurda, E., \& Garrett, P. (2014). Language policies and practices in the internationalisation of higher education on the European margins: An introduction. Journal of Multilingual and Multicultural Development, 35(4), 311-317. https://doi.org/10.1080/01434632.2013.874430

Coyle, D., Hood, P., \& Marsh, D. (2010). Content and language integrated learning. Cambridge University Press.
Dafouz, E., \& Smit, U. (2016). Towards a dynamic conceptual framework for English-medium education in multilingual university settings, Applied Linguistics, 37(3), 397-415. https://doi.org/10.1093/applin/amu034

Dearden, J., \& Macaro, E. (2016). Higher education teachers' attitudes towards English medium instruction: A three-country comparison. Studies in Second Language Learning and Teaching, 6(3), 455-486. https://doi.org/10.14746/sllt.2016.6.3.5.

Doiz, A., Lasagabaster, D., \& Sierra, J. M. (2012).

English-medium instruction at universities: Global challenges. Multilingual Matters. https://doi.org/10.21832/9781847698162

Eagly, A. H., \& Chaiken, S. (1993). The psychology of attitudes. Harcourt.

Eagly, A. H., \& Chaiken, S. (2007). The advantages of an inclusive definition of attitude. Social Cognition, 25(5), 582-602. https://doi.org/10.1521/soco.2007.25.5.582

Gnutzmann, C., \& Intemann, F. (2008). Introduction: The globalization of English. Language, politics, and the English language classroom. In C. Gnutzmann \& F. Intemann (Eds.), The globalisation of English and the English language classroom (pp. 9-24). Gunter Narr Verlag.

Gnutzmann, C., Jackisch, J., \& Rabe, F. (2015). Communicating across Europe. What German students think about multilingualism, language norms and English as a lingua franca. In A. Linn, N. Bermel, \& G. Ferguson (Eds.), Attitudes towards English in Europe (pp. 165-192). Walter de Gruyter.

https://doi.org/10.1515/9781614515517-009

Jenkins, J. (2006). Points of view and blind spots: ELF and SLA. International Journal of Applied Linguistics, 16(2), 137-162. https://doi.org/10.1111/j.14734192.2006.00111.x.

Jenkins, J. (2019). English medium instruction in higher education: The role of English as a lingua franca. In X. Gao (Ed.), Second handbook of 
English teaching (pp. 91-108). Springer. https://doi.org/10.1007/978-3-030-02899-2_7

Jenkins, J., Cogo, A., \& Dewey, M. (2011). Review of developments in research into English as a lingua franca. Language Teaching, 44(3), 281-315. https://doi.org/10.1017/S0261444811000115

Jenkins, J., Modiano, M., \& Seidlhofer, B. (2001). EuroEnglish. English Today, 17(4), 13-19. https://doi.org/10.1017/S0266078401004023

Jensen, C., \& Thøgersen, J. (2011). Danish university lecturers' attitudes towards English as the medium of instruction. Ibérica, 22, 13-34.

Kachru, B. B. (1985). Standards, codification and sociolinguistic realism: The English language in the outer circle. In R. Quirk \& H. G. Widdowson (Eds.), English in the world: Teaching and learning the language and literatures (pp. 11-30). Cambridge University Press.

Klaassen, R. (2001). The international university curriculum: Challenges in English-medium engineering education. [Doctoral dissertation, Delft University of Technology].

https://repository.tudelft.nl/islandora/object/uuid\% 3Adea78484-b8c2-40d0-9677-6a508878e3d9

Knight, J. (2004). Internationalization remodelled: Definition, approaches, and rationales. Journal of Studies in International Education, 8(1), 5-31. https://doi.org/10.1177/1028315303260832

Lo, Y. Y., \& Macaro, E. (2015). Getting used to content and language integrated learning: what can classroom interaction reveal? The Language Learning Journal, 43(3), 239-255. https://doi.org/10.1080/09571736.2015.1053281

Martin, J. R., \& White, P. R. R. (2005). The evaluation of language. Palgrave Macmillan. https://doi.org/10.1057/9780230511910

Mauranen, A., Hynninen, N., \& Ranta, E. (2010). English as an academic lingua franca: The ELFA project. English for Specific Purposes, 29(3), 183190. https://doi.org/10.1016/j.esp.2009.10.001

Modiano, M. (2000). Rethinking ELT, and mid-atlantic English: a communicative strategy. English Today,
$16,28-34$.

https://doi.org/10.1017/S0266078400011603

Modiano, M. (2007). Euro-English from a "deficit linguistics” perspective? World Englishes, 26, 525-33. https://doi.org/10.1111/j.1467971X.2007.00526.X.

Mollin, S. (2006). Euro-English: Assessing variety status. Gunter Narr Verlag.

Lanvers, U., \& Hultgren, A. K. (2018). The Englishization of European education: Foreword. European Journal of Language Policy, 10(1), 1-11. https://doi.org/10.3828/ejlp.2018.1

Nashaat-Sobhy, N. (2017). Mapping student and lecturer perspectives: Use of L1 in a CLIL oriented context. V Buenas Prácticas de Innovación Docente en el Espacio de Educación Superior (pp. 195-212). Ediciones Universidad San Jorge.

O’Donnell, M. (2013). UAM CorpusTool version 3.0. http://corpustool.com/Documentation/UAMCorpu sToolTutorial3.0.pdf

Pitzl, M.-L. (2017). Creativity, idioms and metaphorical language in ELF. In J. Jenkins, W. Baker, \& M. Dewey (Eds.), The Routledge handbook of English as a lingua franca (pp. 233-243). Routledge. https://doi.org/10.4324/9781315717173-20

Sánchez-García, D. (2020). Mapping lecturer questions and their pedagogical goals in Spanish- and English-medium instruction. Journal of Immersion and Content-Based Language Education, 8(1), 28-52. https://doi.org/10.1075/jicb.18016.san

Selinker, L. (1972). Interlanguage. International Review of Applied Linguistics, 10, 209-231.

https://doi.org/10.1515/iral.1972.10.1-4.209

Smit, U. (2017). Beyond monolingualism in higher education. A language policy account. In J. Jenkins, W. Baker, \& M. Dewey (Eds.), The Routledge handbook of English as a lingua franca (pp. 387-399). Routledge. https://doi.org/10.4324/9781315717173-32

Spolsky, B. (2003). Language policy. Cambridge University Press. https://doi.org/10.1017/CBO9780511615245 
Smit, U., \& Dafouz, E. (2012). Integrating content and language in higher education: An introduction to English-medium policies, conceptual issues and research practices across Europe. AILA

Review, 25(1), 1-12.

https://doi.org/10.1075/aila.25.01smi

Tatzl, D. (2011). English-medium masters’ programmes at an Austrian university of applied sciences: Attitudes, experiences and challenges. Journal of English for Academic Purposes, 10(4), 252-270. https://doi.org/10.1016/j.jeap.2011.08.003

Valcke, J., \& Alfaro, E. R. (2016). It takes two to tango: Online teacher tandems for teaching in English. In S. Jager, M. Kurek, \& B. O’Rourke (Eds.), New directions in telecollaborative research and practice: Selected papers on the second conference on telecollaboration in higher education (pp. 171-178). https://doi.org/10.14705/rpnet.2016.telecollab2016 .504

Vinke, A. (1995). English as the medium of instruction in Dutch engineering education. [Doctoral dissertation, Delft University of Technology]. TUDelft.

https://repository.tudelft.nl/islandora/object/uuid:4 91b55f9-fbf9-4650-a44dacb9af8412a8?collection=research

Van Veen, K., \& Sleegers, P. (2006). How does it feel? Teachers' emotions in a context of change. Journal of Curriculum studies, 38(1), 85-111. https://doi.org/10.1080/00220270500109304

VOICE (2013). The Vienna-Oxford international corpus of English (version 2.0 XML). http://www.univie.ac.at/voice

Wilson, T. D., Lindsey, S. T., \& Schooler, T. Y. (2000). A model of dual attitudes. Psychological Review, 107(1), 101-26. https://doi.org/10.1037/0033295X.107.1.101

Young, T. J., \& Walsh, S. (2010). Which English? Whose English? An investigation of 'non-native' teachers' beliefs about target varieties. Language, Culture and Curriculum, 23(2), 123-137. https://doi.org/10.1080/07908311003797627 